\title{
Search Methods for Evacuation Routes during Torrential Rain Disasters Using Genetic Algorithms and GIS
}

\author{
Koichiro Tani ${ }^{1}$, Kayoko Yamamoto ${ }^{2 *}$ \\ ${ }^{1}$ Department of Informatics and Engineering, University of Electro-Communications, Tokyo, Japan \\ ${ }^{2}$ Graduate School of Informatics and Engineering, University of Electro-Communications, Tokyo, Japan \\ Email: ^kayoko.yamamoto@uec.ac.jp
}

How to cite this paper: Tani, K. and Yamamoto, K. (2020) Search Methods for Evacuation Routes during Torrential Rain Disasters Using Genetic Algorithms and GIS. Journal of Geographic Information System, 12, 256-274.

https://doi.org/10.4236/jgis.2020.123016

Received: June 1, 2020

Accepted: June 27, 2020

Published: June 30, 2020

Copyright $\odot 2020$ by author(s) and Scientific Research Publishing Inc. This work is licensed under the Creative Commons Attribution International License (CC BY 4.0).

http://creativecommons.org/licenses/by/4.0/

\begin{abstract}
The present study aims to propose a method to search for the most appropriate evacuation routes that take calorie consumption required for evacuees to reach evacuation sites into consideration, by focusing on disasters caused by heavy rainfall, and using genetic algorithm (GA) and geographic information system (GIS). Specifically, GA was used to design and develop an evacuation route search algorithm and 4 parameters including the number of generations, mutation rate number of individuals and crossover rate were set by conducting sensitivity analyses. Additionally, GIS was also used to create road network data and contour data for digital maps and calculate the altitude of each crossover point. Based on these, the necessary calorie consumption to reach evacuation sites for each route was calculated, and that made it possible to derive the several evacuation routes with the small values unlike other methods. By using GA and GIS to suggest detailed evacuation routes, which take the necessary calories required to reach evacuation sites into consideration, it can be expected that the present study should contribute to the decision-making of evacuees. Additionally, as the method is based on public information, the method has high spatial and temporal repeatability. Because evacuation routes are proposed based on quantified data, the selected evacuation routes are quantitatively evaluated, and are an effective indicator for deciding on an evacuation route. Additionally, evacuation routes that accurately reflect current conditions can be derived by utilizing detailed information as data.
\end{abstract}

\section{Keywords}

Torrential Rain Disasters, Evacuation Route, Evacuation Site, Calorie Consumption, Genetic Algorism (GA), Geographic Information Systems (GIS) 


\section{Introduction}

Disasters related to heavy rain caused by global warming have become a global issue, as they have frequently occurred around the world in recent years. Japan has suffered immense damage from the Kanto-Tohoku Heavy Rainfall in 2015, the Nishi-Nihon Heavy Rainfall in 2018, and the Typhoon No. 19 in 2019. It is important to strengthen disaster prevention and reduction measures as intensified damage caused by natural disasters around the world can be expected also in the future. "Disaster prevention" is a disaster measure to prevent disasters. On the other hand, "disaster reduction" is a disaster measure with the aim of minimizing the damage caused by disasters. The concept of "disaster reduction" drew much attention after the Great Hanshin-Awaji Earthquake (1995), and was recognized as important along with "disaster prevention" after the experience from the Great East Japan Earthquake (2011).

According to the "Public opinion survey on disaster prevention" (2017) [1] by the Cabinet Office, the highest percentage of answers concerning what type of information should be increased was that of "evacuation locations and routes for disasters". While information on areas with a high risk of flooding and evacuation locations can be easily obtained by looking at hazard maps, there is hardly any public information concerning evacuation routes. Heavy rainfall may cause roads to be flooded, making it impossible for people to use the roads they would normally use to go to the evacuation sites. Therefore, in order for people to calmly evacuate during heavy rainfalls, it is important for each individual to gather various information related to evacuation routes before a disaster.

Based on the background provided above, the present study aims to propose a method to search for the most appropriate evacuation routes among many other routes, by using genetic algorithm (GA) and geographic information system (GIS). By using GA and GIS to suggest detailed evacuation routes, which take the necessary calories required to reach evacuation sites into consideration, it can be expected that the present study should contribute to the decision-making of evacuees as well as the improvement of disaster prevention awareness.

In the present study, first of all, in Section 3, an evacuation route search algorithm will be designed and developed using GA with the purpose of providing evacuation routes that enable people to reach the evacuation sites with minimal calorie consumption during disasters related to heavy rainfalls. In Section 4, 2 target areas with different geographical conditions will be selected referring the flooding hazard maps. Additionally, calculations of the altitude for each traffic intersection as well as the preparation of road network data and contour data of the target areas will be made using GIS. In Section 5, sensitivity analyses will be used to set the GA parameters. Finally, in Section 6, the evacuation route search algorithm will be applied to the target areas and the appropriate evacuation routes will be suggested in detail.

According to Yamamoto $(2009,2015,2019)$ [2] [3] [4], GIS has 4 main functions including the database creation function, the data analysis function, the 
information provision and sharing function, as well as the decision-making support function, and is identified as a system that connects the real world with the virtual world. In Section 4, the database creation and data analysis functions will be utilized to prepare road network data and contour data as well as calculate the altitude of each traffic intersection of the target areas. Additionally, in Section 6, the data analysis and information provision and sharing functions will be utilized to visualize evacuation routes derived in the present study onto digital maps. ArcGIS Pro 2.3.2 provided by the Environmental Systems Research Institute, Inc. (ESRI) will be used for the GIS in the present study.

On the other hand, GA is a modeled engineering mechanism of animal genetics and evolution, and is a type of evolutionary algorithm used to inductively search for optimal solutions toward various problems, while repeating genetic operations such as selection, crossover and mutation (Holland, 1975) [5]. It is necessary to determine strict individual superiority for GA, and the conformance degree is considered to be a superiority indicator. In general, individuals that have a higher conformance degree (evaluation value) are considered to be superior and can reproduce more easily. One advantage of using GA for the present study is that approximate solutions for optimal solutions to complicated problems can be generated in a short period of time. Secondly, various solutions can be generated until convergence, as GA uses random selections instead of consistently deriving only optimal solutions.

\section{Related Work}

As mentioned in the previous section, the present study aims to propose a method to search for the most appropriate evacuation routes. In the academic fields related to the present study, there a lot of previous studies targeting evacuation route, and they are divided into two groups without and with adopting GA. One is 1) the studies concerning evacuation routes without adopting GA, and the other is 2) the studies concerning optimal evacuation routes with adopting GA.

Regarding (1) the studies concerning evacuation routes without adopting GA, Sato et al. (2008) [6] used converted walking distances that consider calorie consumption in order to reveal the walking zone in actual urban spaces. Additionally, Murabayashi (2008) [7] adopted Dijkstra's algorithm to create a walking map that takes hills into consideration. Campos et al. (2012) [8] proposed a method which iteratively applies a heuristic algorithm to define two independent paths from the disaster area to each shelter for vehicle flow allocation in evacuation route planning. García-Ojeda et al. (2013) [9] proposed a method for developing-evacuation-routes via the P-graph framework. Mishima et al. (2014) [10] proposed a two-way evacuation routes based on residents' perceptions in a historic preservation area. Focael et al. (2014) [11] proposed a simulation model to find out optimum evacuation routes, during a tsunami using the Ant Colony Optimization (ACO) algorithms. Yamamoto et al. (2017) [12] also adopted the ACO algorithm to quantitatively evaluate the safety of urban evacuation routes 
during earthquakes.

Lim et al. (2015) [13] presented a reliability-based evacuation route planning model that seeks to find the relationship between the clearance time, number of evacuation paths and congestion probability during an evacuation. Cuesta et al. (2017) [14] proposed a real-time decision methodology for the selection of optimal evacuation routes for buildings, using the solution optimization algorithm based on stochastic evacuation model predictions. Álvarezet al. (2018) [15] identified and classified the urban micro-vulnerabilities in tsunami evacuation routes. Lujak et al. (2019) [16] researched the agility of evacuation routes in relation to dynamically changing unpredictable hazardous conditions in smart space networks, adopting the centrality measures. Additionally, Yoshitsugi et al. (2019) [17] used the slime mold algorithm to design and develop an algorithm that can set multiple evacuation starting and finishing points, simultaneously obtain multiple routes, and assign the priority order.

Regarding (2) the studies concerning optimal evacuation routes with adopting GA, Li et al. (2010) [18] proposed a multi-objective evacuation route assignment model to plan an optimal egress route set for the individual evacuees. Łozowicka (2012) [19] used GA and genetic programming designated evacuation routes for different groups of people from ships and land facilities. Loland et al. (2013) [20] applied a multi-objective GA with five different fitness functions that use heuristics to develop to pick the best evacuation plan out of the pool of potential solutions. Shimura et al. (2014) [21] used a multi-objective GA to design and develop an algorithm that can search for optimal evacuation routes during earthquakes. Goerigk et al. (2014) [22] proposed a multi-criteria macroscopic evacuation planning problem, adopting mixed-integer program and a GA. Pourrahmani et al. (2019) [23] presented an evacuation vehicle routing problem to design evacuation routes for public vehicles, using fuzzy credibility theory and GA. Ikeda et al. (2016) [24] proposed an evacuation route planning for safety route guidance system after natural disaster using multi-objective GA. Gomes et al. (2017) [25] used a GA for flood detection and evacuation route planning. Li et al. (2019) [26] introduced a technique to design the level of service (LOS) for facilities or sub spaces of buildings for the purpose of evacuation planning including routes and paths.

The previous studies within the related academic fields mentioned above mainly target earthquakes, tsunamis and large-scale fires, and hardly consider disasters related to heavy rainfalls. Therefore, the focus is mainly on horizontal evacuations, while vertical evacuations are rarely considered when deriving evacuation routes. However, vertical evacuations are essential as floods and landslides occur due to heavy rainfalls. Thus, the present study mainly focuses on vertical evacuations during heavy rainfall disasters based on the results of the aforementioned studies. Additionally, based on the results of (2) the studies concerning optimal evacuation routes with adopting GA, it made clear the usefulness to adopt GA in addition to GIS to derive optimal evacuation routes. In this way, compared to 
such previous studies, the present study demonstrates its originality by focusing on evacuation methods for heavy rainfall disasters, which have not been previously considered, as well as using GA and GIS to propose search methods for optimal routes that take the calorie consumption required to reach the evacuation sites into consideration.

\section{Search Methods of Evacuation Routes Using GA and GIS}

\subsection{Overview of Function Design of Evacuation Route Search Algorithms}

In the present study, Python 3.7 was used as the programming language to design the evacuation route search algorithm. Figure 1 shows the following process of the evacuation route search algorithm. Following this process, the next section will describe the details of the evacuation route search algorithm uniquely developed in the preset study.

1) Obtainment of the adjacent information between nodes (road network data)

Information between each node is stored in the CSV data and entered into the GA. Section 4.5 will provide a more detailed description of the CSV data.

2) Generation of the initial group

Initial groups are set by randomly generating routes between the evacuation starting and finishing points of the selected number of group sizes (number of individuals; the number of evacuation routes in the present study). The selected number of group sizes will be explained in more detail in section 5.3.

3) Evaluation of the conformance degree

The conformance degree of each evacuation route is calculated.

4) Selection

Based on the conformance degree calculated in 3 ), the reproduction groups

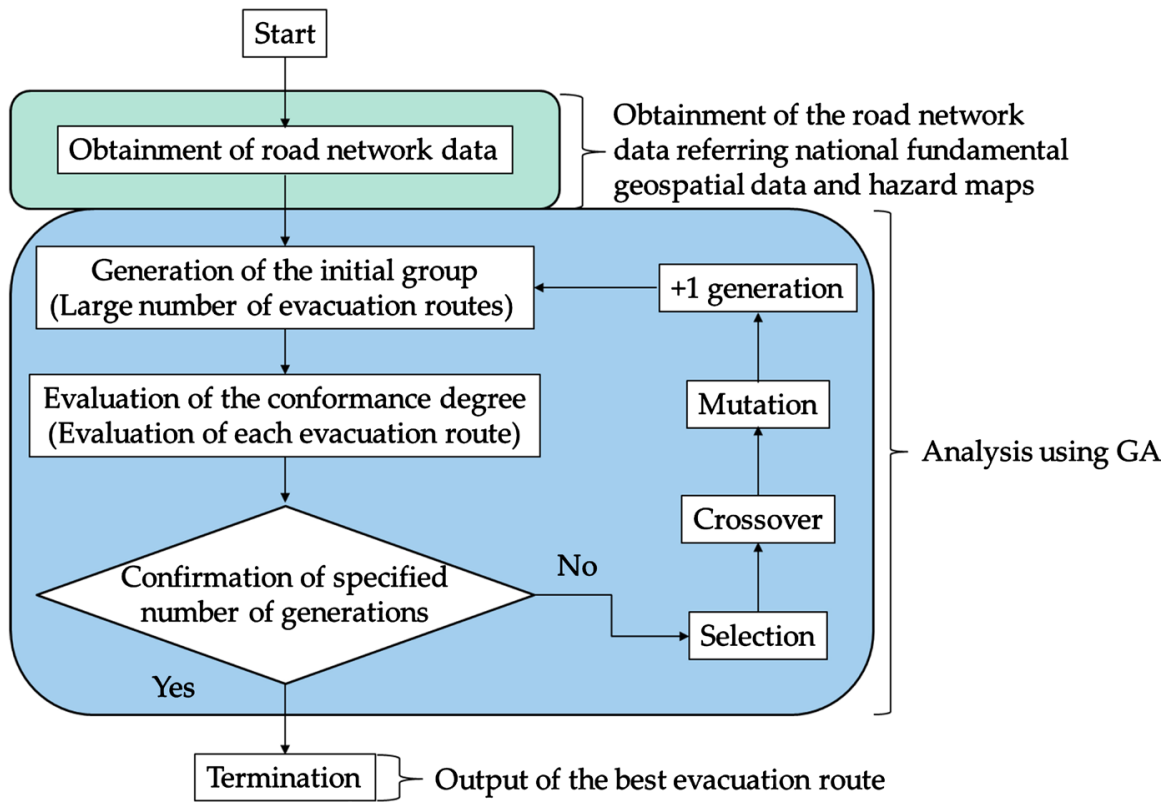

Figure 1. Process of the evacuation route search algorithm used in the present study. 
(the evacuation routes in the present study) are selected. A combination of roulette wheel selection and elite selection method will be used.

5) Crossover

Based on the groups selected in 4), 2 evacuation routes will be randomly selected to become parents. Additionally, a crossover point will be randomly selected and 2 evacuation routes will be generated to become children by switching the evacuation routes after the crossover point.

6) Mutation

An evacuation route will be randomly selected from within the group and a new evacuation route will be generated by replacing it with other evacuation route after the mutation point.

\subsection{Development of Evacuation Route Search Algorithm}

\subsubsection{Obtainment of Adjacent Information between Nodes}

The CSV data where the cost between nodes is stored is converted into an adjacent list and entered into the GA. The adjacent list has a triple structure and contains adjacent information which is the adjacent nodes of each node as well as the cost values to the adjacent nodes. For example, the adjacent information for node No. 0 is stored in the adjacent list No. 0. Figure 2 shows an example of an adjacent list.

\subsubsection{Expression Method for Evacuation Routes}

The lists arranging each node that goes through evacuation starting points to the fishing points in order are expressed as evacuation routes. Figure 3 shows an example of the expression method for an evacuation route based on a virtual route.

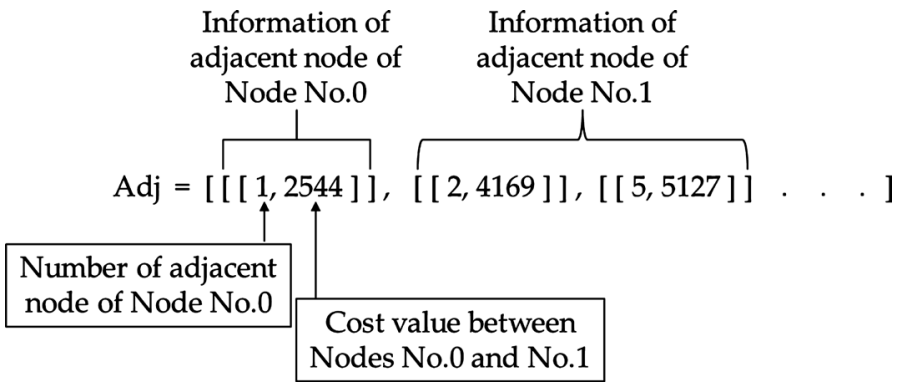

Figure 2. Example of an adjacent list.

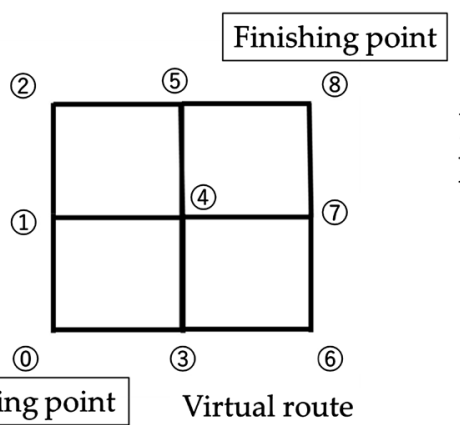

Ex)

Route $1 \quad 0 \rightarrow 1 \rightarrow 2 \rightarrow 5 \rightarrow 8$

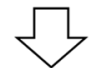

$[0,1,2,5,8]$

Starting point Virtual route

Figure 3. Example of expression methods for evacuation routes. 


\subsubsection{Generating the Initial Group}

$\mathrm{N}$ number of routes, which connect evacuation starting points with destination evacuation sites are selected at random and stored in a double structured list. The starting point is set as 0 while the finishing point as 8 , and a virtual route is made as shown in Figure 3. Each evacuation route is expressed as in Figure 3 of the previous section. Additionally, Figure 4 shows an example of the initial group list. $[0,1,2,5,8]$ of Figure 4 indicates a route and is the route between the starting point and finishing point in shown in Figure 3.

\subsubsection{Evaluation of the Conformance Degree}

In order to suggest appropriate evacuation routes, calorie consumption required to reach evacuation sites is taken into consideration in the present study. The necessary calorie consumption for each route is calculated by referring the metabolic energy Equation (1) to create the route calorie consumption Equation (2) which incorporates walking time. This Equation (2) is used to calculate the calorie consumption for each route.

Furthermore, basal metabolic rate is calculated using Equation (3). The variables of Equation (3) concerning weight and height are set to be that of males over 70 years old who are vulnerable to disasters. However, as the basal metabolic rate is a fixed value and can be considered an invariable, route evaluations do not change depending on age or gender. On the other hand, as the relative metabolic rate changes according to the slope of evacuation routes, the evaluation of evacuation routes is dependent on this value. Relative metabolic rates are calculated using Equation (4) which was proposed by Sato et al. (2008).

Because Equation (3) is used for evacuation routes between each node, $\mathrm{T}$ represents the travel time between nodes. As walking speed is set at $80 \mathrm{~m} / \mathrm{m}$ with the precondition of Equation (4), this speed is applied to other equations.

$$
E=(R M R+1.2) \times \text { Basal metabolic rate }
$$

$E:$ Metabolic energy;

$R M R$ : Relative metabolic rate;

$$
K=(R M R+1.2) \times \text { Basal metabolic rate } \times T
$$

$K$ : Route calorie consumption;

$R M R$ : Relative metabolic rate;

T: Travel time;

Basal metabolic rate $=$ Basal metabolic reference value $\times$ Reference weight

$$
B M R=3.113 \times \exp (4.614 \times \text { Slope })
$$

\subsubsection{Selection}

The selection methods used in the present study are the roulette wheel selection

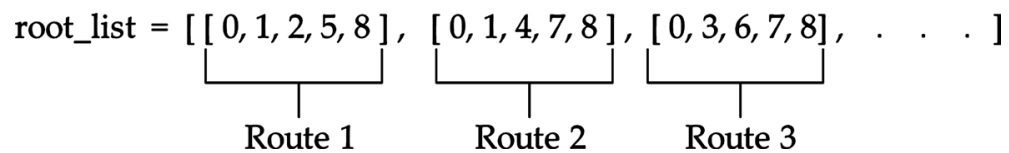

Figure 4. Example of initial group list. 
and the elite selection. The former selects individuals with the probability according to their conformance degrees, and the selection rate can be expressed in Equation (5).

$$
p_{i}=\frac{f_{i}}{\sum_{k=1}^{N} f_{k}}
$$

$f_{i}$ : Conformance degree of individual $i$;

$N$ : Number of individuals.

The latter is a method where an arbitrary number of individuals with high conformance degrees are selected from within a group. Because optimal solutions tend to be local when only using the elite selection, it is best to combine this method with the roulette wheel selection. In the present study, for the group of $N$ individuals, the elite selection will be applied once, while the roulette wheel selection will be applied $N-1$ times.

\subsubsection{Crossover}

2 individuals are selected from a group based on the set crossover probability C. The selected individuals are called parents. If the 2 individuals have the same nodes, a crossover is conducted by selecting a random crossover point. New individuals produced by the crossover point are called children. Figure 5 shows the following operation process concerning the crossover.

1) 2 parent individuals are selected from the group after the step in the previous section. However, crossovers are not conducted if the selected 2 individuals have the same line of elements, and the individuals are added to the next-generation group.

2) Determine whether the 2 parents have overlapping nodes besides the evacuation starting and finishing points.

3) If there are no overlapping nodes, a crossover is not conducted and the individuals are directly added to the next-generation group.

4) If overlapping nodes are found, 1 node is randomly selected from the overlapping nodes and a crossover point is determined.

5) Nodes of the 2 parent individuals after the crossover point are swapped and 2 children are generated. These 2 new individuals are added to the next-generation group.

6) Any loops found in the generated children are removed.

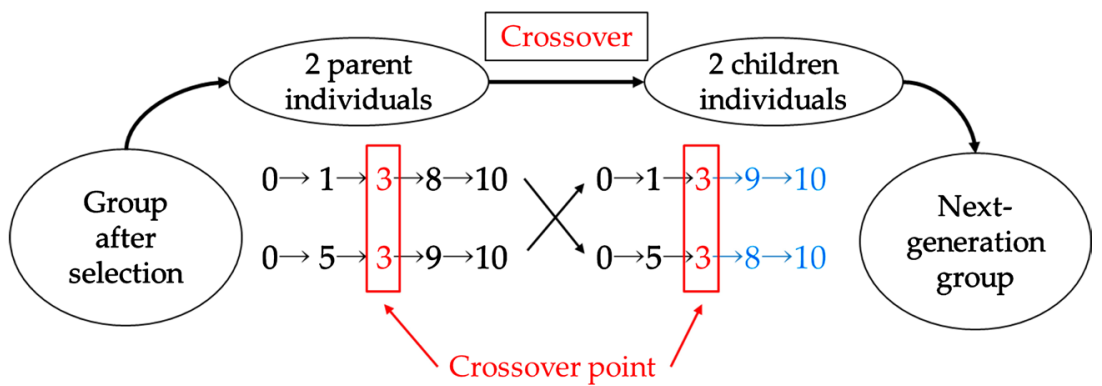

Figure 5. Operation process concerning crossover. 


\subsubsection{Mutation}

1 individual is selected from the group of next-generation generated in the previous section, and mutation is conducted using the set mutation probability $\mathrm{M}$. Figure 6 shows the following mutation process concerning the mutation.

1) 1 individual is randomly selected from the next-generation group created in the previous section.

2) The mutation point is determined by randomly selecting 1 node from the nodes excluding evacuation starting and finishing points among the selected individuals.

3) A route connecting the mutation point to the finishing point is randomly created.

4) A new route is created by swapping the route after the mutation point of the selected individual with the route created in (3). This route will be returned to the next-generation group.

5) Any loops found in the newly created evacuation route are removed.

\section{Selection of Target Areas and Utilized Data}

\subsection{Selection of Target Areas}

As mentioned in Sections 1 and 2, the present study targets vertical evacuations as floods and landslides occur due to heavy rainfalls. Referring the disaster cases database developed by the National Research Institute for Earth Science and Disaster Resiliense [27], Setagaya Ward in Tokyo Metropolis, and Asakita Ward in Hiroshima City, were selected as the target areas as explained in detail below. Setagaya Ward is located along the Tama River which flooded during Typhoon No. 19 in 2019. Asakita Ward also suffered much damage from heavy rain in August 2014 and July 2018.

\subsubsection{Setagaya Ward in Tokyo Metropolis}

The present study utilizes the calorie consumption equation to evaluate evacuation routes. The differences in evaluation values are caused by areas with different altitudes. Therefore, as there is a higher risk of floods during heavy rainfalls,

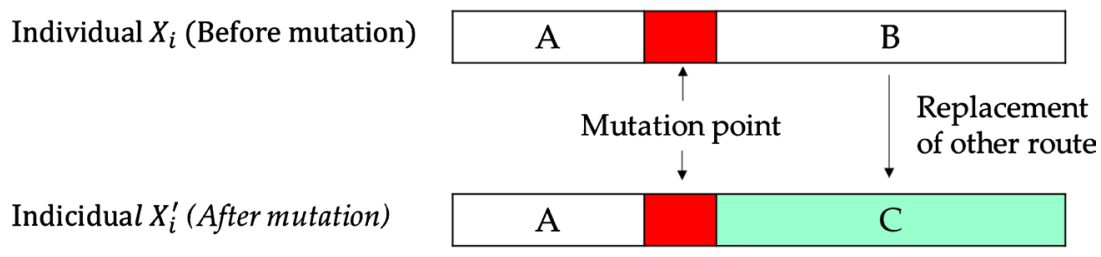

Ex) Mutation point is 2

$$
\begin{array}{ll}
\text { Individual } X_{i} \text { (Before mutation) } & \text { Ex) } 0 \rightarrow 1 \rightarrow 2 \rightarrow 5 \rightarrow 6 \rightarrow 10 \\
\text { Indicidual } X_{i}^{\prime} \text { (After mutation) } & \text { Ex) } 0 \rightarrow 1 \rightarrow 2 \rightarrow 6 \rightarrow 9 \rightarrow 10
\end{array}
$$

Figure 6. Operation process concerning mutation. 
areas along the Tama River with low altitudes where people will need to evacuate to higher altitudes were investigated. Based on the results, 1-chome Todoroki and 2-chome Oyamadai in Setagaya Ward were selected. The difference between the altitude of north and south is significant in these areas and Oyamadai Elementary School is the designated evacuation site.

\subsubsection{Asakita Ward in Hiroshima Prefecture}

Heavy rainfall can cause landslides as well as floods. In contrast with floods, people must evacuate from high places to lower altitudes in the case of landslides. Therefore, the present study will focus on 2-chome and 3-chome Kameyama as well as 5-chome and 7-chome Kabe which are all designated as special cautionary areas and cautionary areas for landslide disasters. The difference between the altitude of east and west is significant in these areas and Kabedai Elementary School is the designated evacuation site.

\subsection{Selection of the Evacuation Starting and Finishing Points within the Target Areas}

\subsubsection{Setagaya Ward in Tokyo Metropolis}

Based on the flood hazard map (Tama River edition) of Setagaya Ward in Tokyo Metropolis [28], the evacuation starting point was set at Tamazutsumi Elementary School and the finishing point was set at Oyamadai Elementary School. Tamazutsumi Elementary School is located near Tama River and the flood depth is considered to be $0.5-3.0 \mathrm{~m}$ according to the hazard map. Oyamadai Elementary School is set as the finishing point as it is the closest evacuation site from Tamazutsumi Elementary School.

\subsubsection{Asakita Ward in Hiroshima City}

Based on the Hiroshima City flood hazard map [29], the evacuation starting point was set at Funayama Inari Shrine, and the finishing point was set at Kabe Elementary School. Funayama Inari Shrine is located on a steep slope and this area is designated as both special cautionary areas and cautionary areas for landslides. Kabe Elementary School is an evacuation site for disasters related to both floods and landslides.

\subsection{Collection and Processing of Data}

Table 1 lists the data and its overviews in the present study.

\subsection{Development of Road Network Data and Calculation of the Altitude of Each Crossover Point Using GIS}

In the present study, GIS is used to place point data in the traffic intersections on the digital map and create road network data by drawing lines to connect the intersections. Additionally, the altitude of each crossover point is calculated based on the contour data which is created using the national fundamental geospatial data provided by the Geospatial Information Authority of Japan. 
Table 1. Data and its overviews.

\begin{tabular}{|c|c|}
\hline Data & Overview \\
\hline $\begin{array}{l}\text { Dietary Reference Intakes for Japanese: } 2020 \text { edition (Ministry of Health, Law and } \\
\text { Welfare) [30] }\end{array}$ & $\begin{array}{l}\text { Calculations of calorie consumption per route for males over } \\
70 \text { years of age }\end{array}$ \\
\hline $\begin{array}{l}\text { Flood hazard map (Tama River edition) data (Setagaya Ward) [28] } \\
\text { Hiroshima City flood hazard map (Hiroshima City) [29] }\end{array}$ & Setting the evacuation starting and finishing points \\
\hline $\begin{array}{l}\text { National Fundamental Geospatial Data (Geospatial Information Authority of } \\
\text { Japan) [31] }\end{array}$ & $\begin{array}{l}\text { Development of road network data and contour data } \\
\text { Calculations of the altitude of each crossover point }\end{array}$ \\
\hline
\end{tabular}

\subsection{Calculation of Route Calorie Consumption between Adjacent Nodes}

The process of calculating the route calorie consumption between adjacent nodes is as shown below.

(1) The distance between adjacent nodes is calculated using the distance measuring tools of GIS and road network data.

(2) The altitude of each node is calculated by contour data.

(3) The slope of each evacuation route is calculated based on the distance between adjacent nodes (1) and the altitude difference between nodes (2).

(4) The slope value calculated in (3) is substituted into Equation (4) to calculate RMR.

(5) The RMR calculated in (3) and the basal metabolic rate calculated in Equation (3) are substituted into Equation (2) and multiplied by the travel time between nodes to calculate the calorie consumption per route.

\section{GA Parameter Settings}

Regarding GA, it is necessary to appropriately set the parameters according to the purpose of the present study, as the optimal parameter values are unclear. The parameters of GA in the present study are the number of generations, mutation rate, number of individuals and the crossover rate. The parameters are set by conducting a sensibility analysis for each of the 4 parameters.

\subsection{Setting of the Number of Generations}

As the sensitive analysis was conducted, the number of generations is determined by grasping the change in cost values of up to 1000 generations and reading the first convergence point. In the present study, cost values were measured 100 times from the first to the $1000^{\text {th }}$ generation, and whether the cost value is converged or not was confirmed every $100^{\text {th }}$ generation as shown in Figure 7. The number of generations was set at 100 after considering the change in cost value average and minimum value.

\subsection{Mutation Rate}

The sensitivity analysis was conducted with the mutation rate at $1 \%, 5 \%, 10 \%$, $15 \%$ and $20 \%$. The cost value was measured 100 times from the $1^{\text {st }}$ generation to 
the $100^{\text {th }}$ generation, and the average and minimum values of each generation were calculated as shown in Figure 8. The mutation rate was set at $5 \%$ which is the lowest cost value after comparing and considering the average and minimum values.

\subsection{Number of Individuals}

The number of individuals in the present study represents the number of routes to the evacuation sites. The optimal solution will be too local if the number of individuals is too small, while the convergence will be delayed and closer to an exhaustive search if there are too many individuals. In the present study, sensitivity analysis is conducted for the number of individuals set at 20,30, 40 and 50. The cost value was measured 100 times from the $1^{\text {st }}$ to the $100^{\text {th }}$ generations, and the average and minimum values of each generation are calculated as shown in Figure 9. The number of individuals was set at 50 which is the lowest cost value after comparing and considering the average and minimum values.

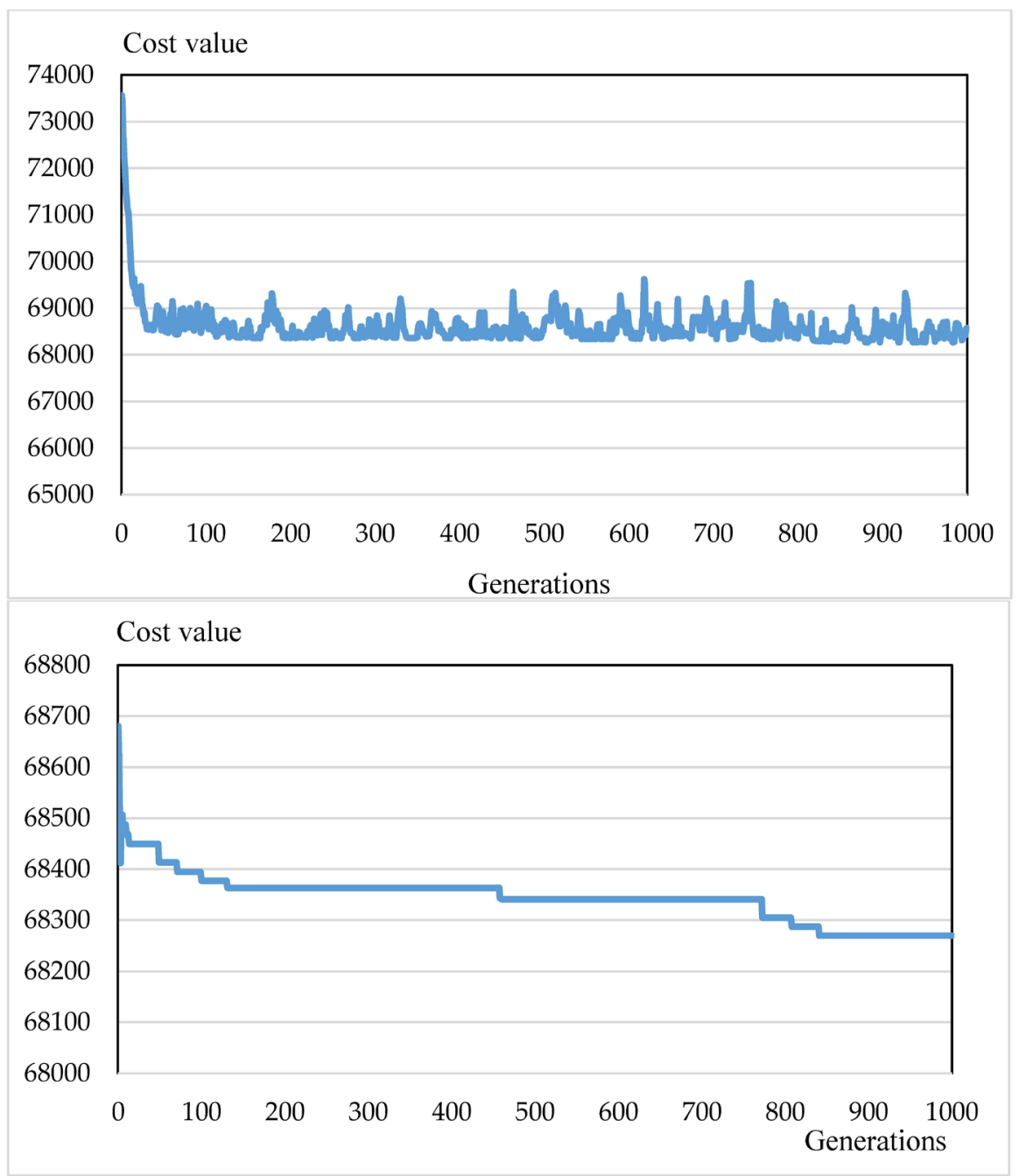

Figure 7. Average value (upper subfigure) and minimum values (lower subfigure) of the number of generations. 


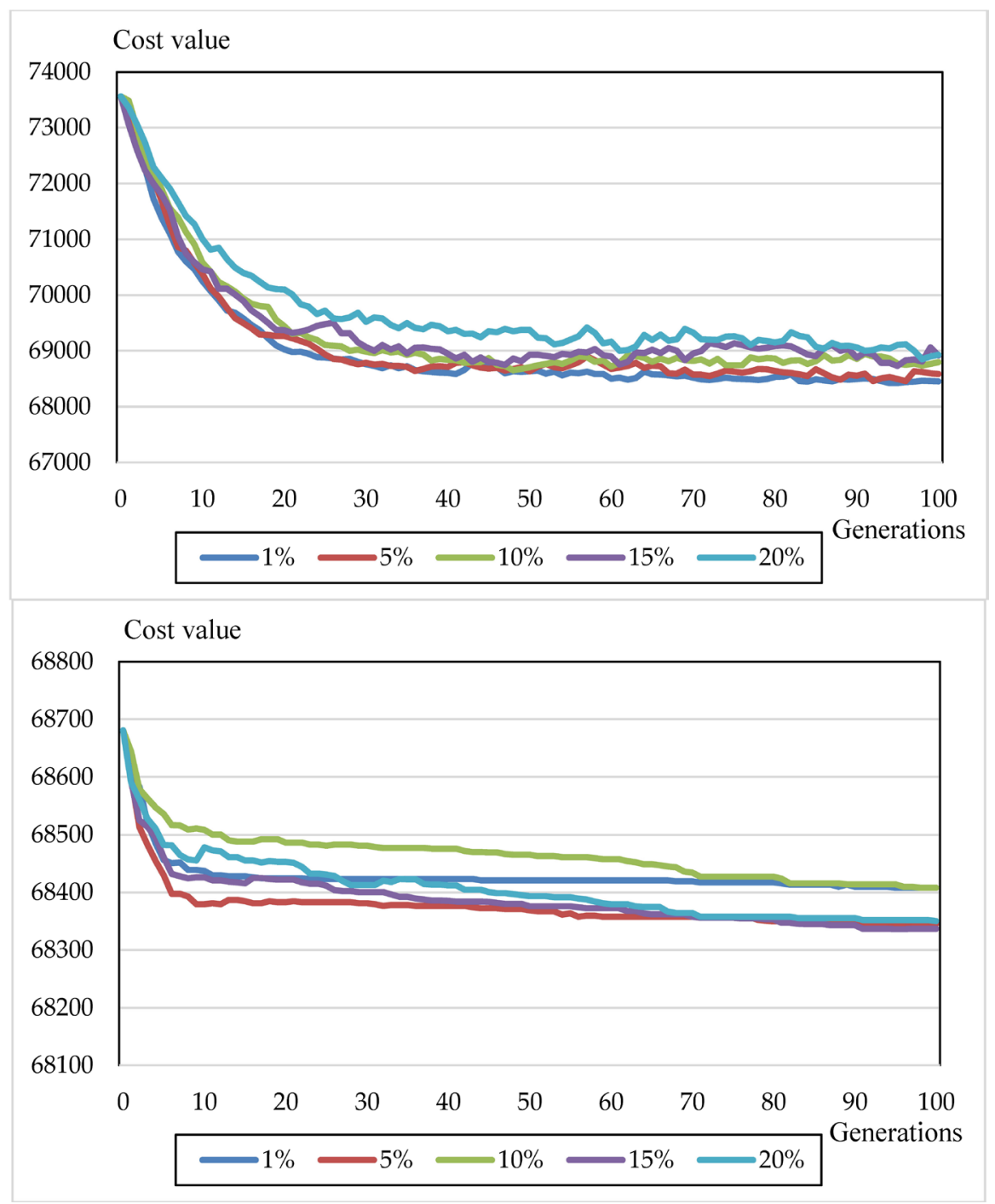

Figure 8. Average value (upper subfigure) and minimum values (lower subfigure) of the mutation rate.

\subsection{Crossover Rate}

The sensitivity analysis for the crossover rate was conducted at $50 \%, 60 \%, 70 \%$, $80 \%, 90 \%$ and $100 \%$. The cost value was measured 100 times from the $1^{\text {st }}$ to the $100^{\text {th }}$ generations, and the average and minimum values of each generation are calculated as shown in Figure 10. The crossover rate was set $100 \%$ which is the lowest cost value after comparing and considering the average and minimum values.

\section{Generation of Evacuation Routes within Target Areas}

\subsection{Generation Results of the Evacuation Routes}

Based on section 5.3, 50 evacuation routes connecting the starting points to the finishing points were generated for each of the 2 target areas. In Figure 11 and Figure 12, the evacuation routes that use the least amount of calories are shown 


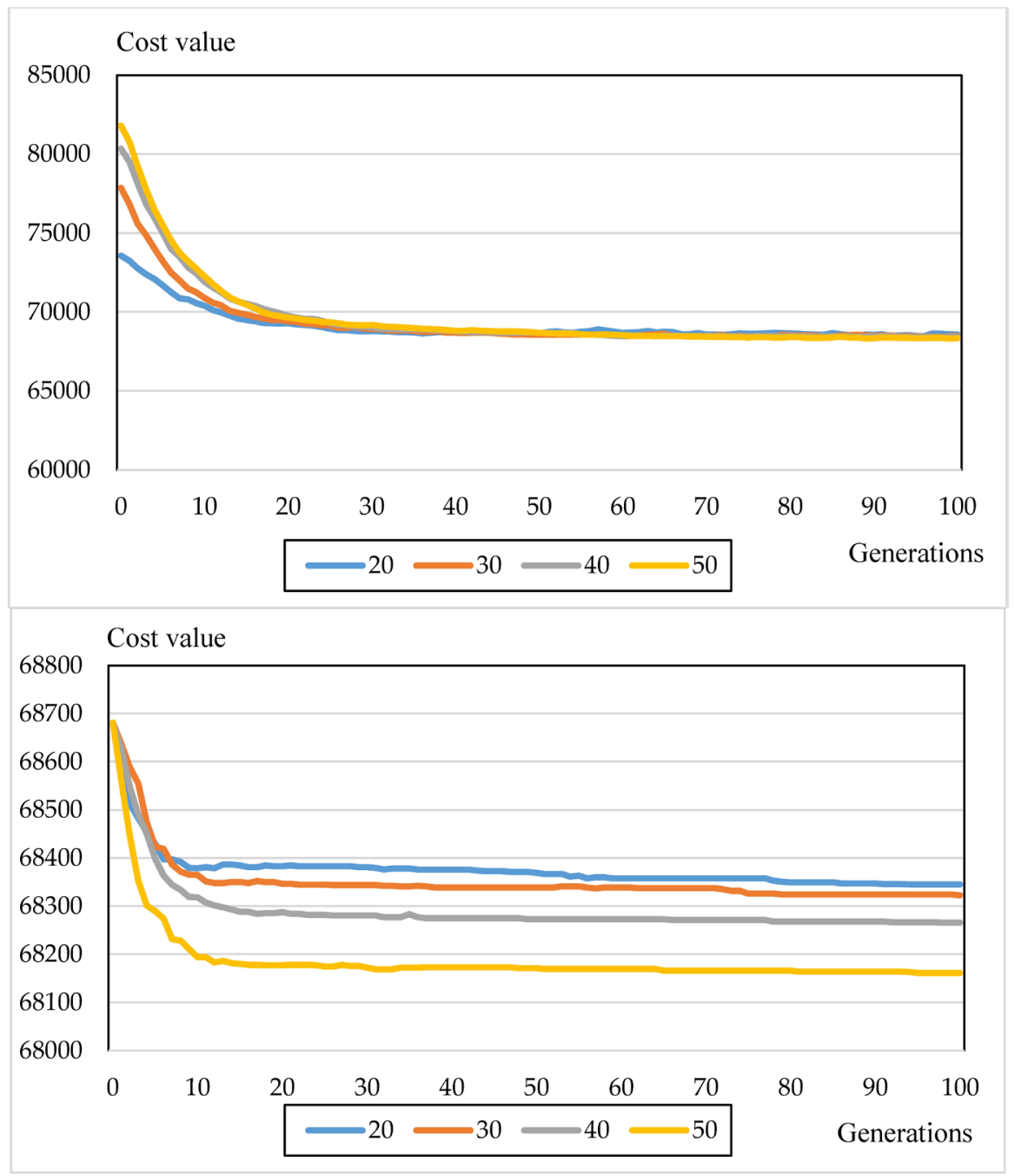

Figure 9. Average value (upper subfigure) and minimum values (lower subfigure) of the number of individuals.

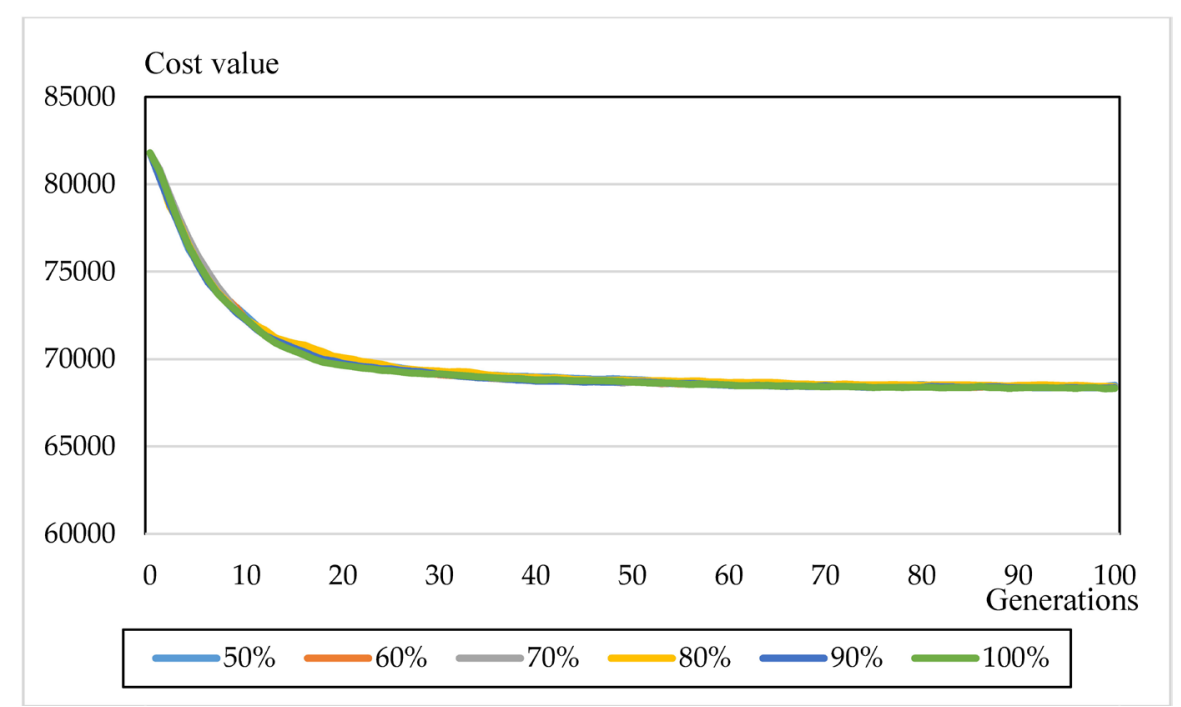




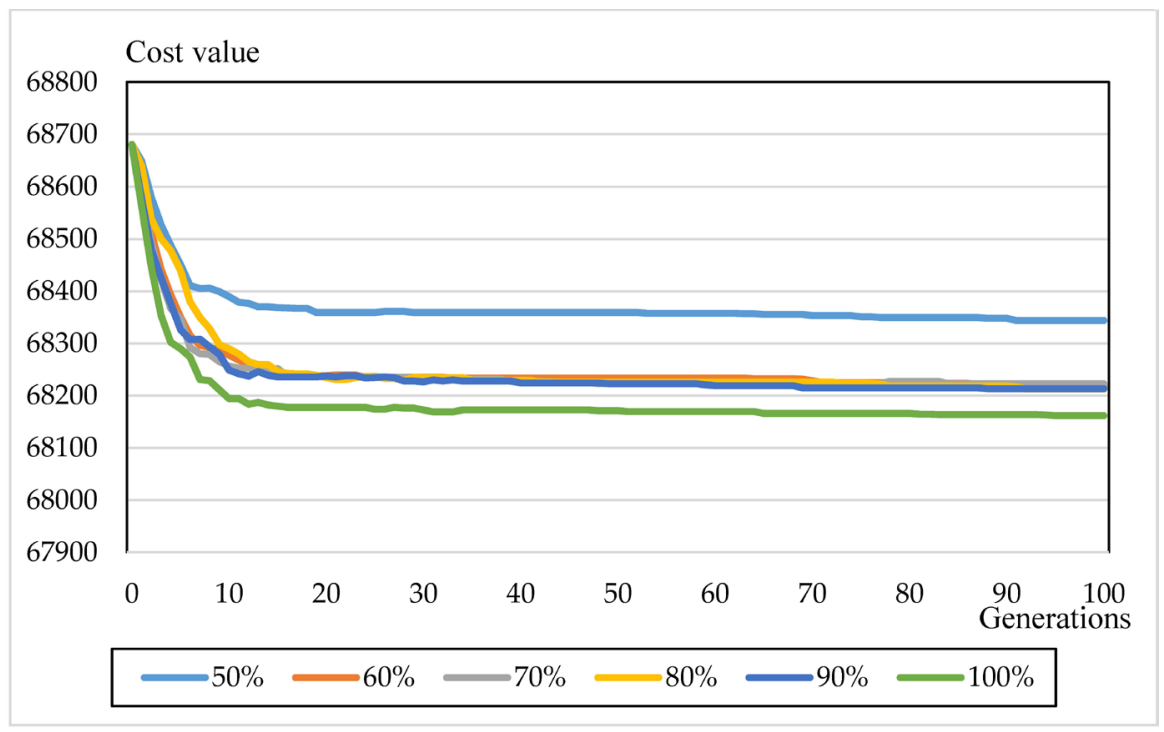

Figure 10. Average value (upper subfigure) and minimum values (lower subfigure) of the crossover rate.

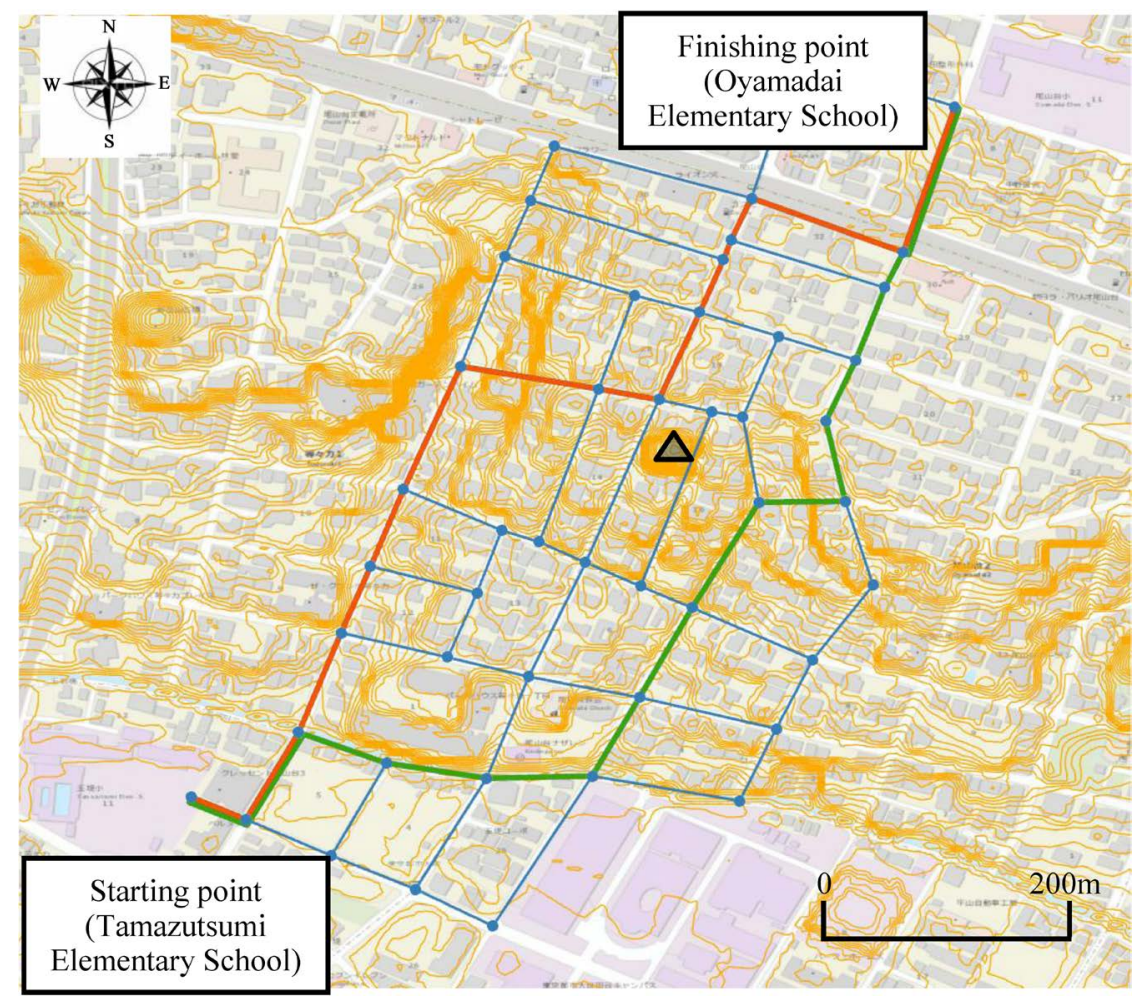

Figure 11. Evacuation routes connecting the starting point to the finishing point in Setagaya Ward, Tokyo Metropolis.

in green, routes that use the 2nd least amount in red, and the contour lines in orange. Regarding both target areas, the evacuation routes that required the least amount of calories were the same routes found using Dijkstra's algorithm. However, the methods used in the present study enable users to search for multiple routes, while only the shortest routes can be found using Dijkstra's algorithm. 


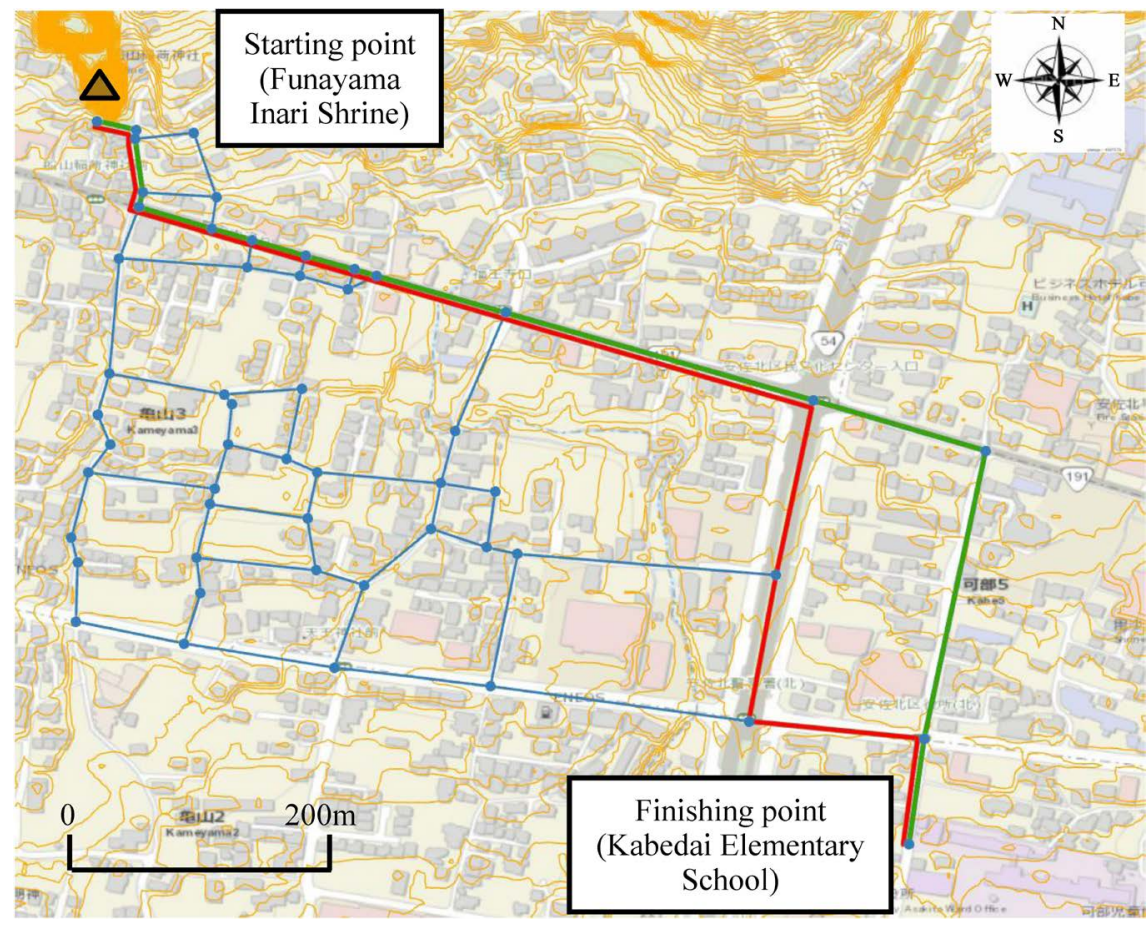

Figure 12. Evacuation routes connecting the starting point to the finishing point in Asakita Ward, Hiroshima Prefecture.

During the disasters related to heavy rainfalls, if the best evacuation routes are damaged, people can select the second best evacuation sites.

\subsection{Discussion}

In the case of Setagaya Ward in Tokyo Metropolis, the target was set for evacuations from low altitudes to higher altitudes. As shown in Figure 11, the central part of this area $(\boldsymbol{\Delta})$ has a point that is higher in altitude than its surrounding area. The 2 evacuation routes generated in the present study go through areas with similar altitudes and avoid places with a significantly high altitude.

On the other hand, in the case of Asakita Ward in Hiroshima City, the target was set for evacuations from high altitudes to lower altitudes. As shown in Figure 12, the west part of this area has a point that is higher $(\mathbf{\Delta})$ in altitude than its surroundings. There was very little difference between the 2 evacuation routes generated by the present study, and they are mostly flat and are along the Japan National Route 191.

Therefore, in areas where people must evacuate from low altitudes to higher altitudes, evacuation routes that are short and avoid steep slopes are selected. In contrast, regarding areas where people must evacuate from high altitudes to lower altitudes, evacuation routes that go down gentle hills without passing through altitudes that are higher than the starting point are selected. Based on these factors, the present study has revealed that evacuation routes with minimum calorie consumption can be generated using the search method for evacuation routes. 


\section{Conclusions}

The conclusion of the present study can be summarized in the following 3 points.

1) The present study focuses on disasters caused by heavy rainfall and proposes the search method for evacuation routes that takes calorie consumption required for evacuees to reach evacuation sites into consideration. Specifically, the first step in the present study was to create an equation based on equations and other data from previous studies to calculate the calorie consumption for each route. Next, GA was used to design and develop an evacuation route search algorithm and 4 parameters including the number of generations, mutation rate number of individuals and crossover rate were set by conducting sensitivity analyses. Additionally, GIS was also used to create road network data and contour data for digital maps and calculate the altitude of each crossover point. Based on these, the necessary calorie consumption to reach evacuation sites for each route was calculated, and that made it possible to derive the evacuation routes with the smallest values.

2) In contrast with the Dijkstra's algorithm and $A^{*}$ algorithm, the search method for evacuation routes proposed in the present study allows several routes to be proposed. Additionally, as the evaluation method is based on public information, it can be effectively applied to other areas or past and future data by obtaining geographic data similar to that of the present study. Therefore, the evaluation method has high spatial and temporal repeatability.

3) Because evacuation routes are proposed based on quantified data, the selected evacuation routes are quantitatively evaluated, and are an effective indicator for deciding on an evacuation route. Additionally, evacuation routes that accurately reflect current conditions can be derived by utilizing detailed information as data.

For future research, the application of the search method for evacuation routes proposed in the present study in other areas, improvement of evaluation accuracy, and the refinement of road data can be raised.

\section{Conflicts of Interest}

The authors declare no conflicts of interest regarding the publication of this paper.

\section{References}

[1] Cabinet Office (2017) Public Opinion Survey on Disaster Prevention. https://survey.gov-online.go.jp/h29/h29-bousai/index.html

[2] Yamamoto, K. (2009) Present State and Future Prospects for GIS as an Environmental Information System: A Case Study of Land-Use Analysis in the Lake Biwa Drainage Basin. Environmental Science, 22, 143-154.

[3] Yamamoto, K. (2015) Social Media GIS for Information Sharing and Support for Local Activities. Kokonshoin, Tokyo.

[4] Yamamoto, K. (2019) Possibility to Utilize Information and Communication Tech- 
nology in Environmental Science. Environmental Science, 32, 26-35.

[5] Holland, J.H. (1975) Adaptation in Natural and Artificial System: An Introductory Analysis with Applications to Biology, Control, and Artificial Intelligence. University of Michigan Press, Ann Arbor.

[6] Sato, E., Yoshikawa, T. and Yamada, A. (2008) Examination of Continuity of Local Living Based on the Converted Walking Distance: Model for Location Planning of Regional Facilities Considering Topographical Condition and Aging Society Part 2. Journal of Architecture and Planning (Transactions of AI), 625, 611-618. https://doi.org/10.3130/aija.73.611

[7] Murabayashi, M. (2012) Walking Map Considering Inclined Planes in Seto City. Graduation Thesis, Nanzan University, Aichi.

[8] Campos, V., Bandeira, R. and Bandeira, A. (2012) A Method for Evacuation Route Planning in Disaster Situations. Procedia-Social and Behavioral Sciences, 54, 503-512. https://doi.org/10.1016/j.sbspro.2012.09.768

[9] Mishima, N., Miyamoto, N., Taguchi, Y. and Kitagawa, K. (2014) Analysis of Current Two-Way Evacuation Routes Based on Residents' Perceptions in a Historic Preservation Area. International Journal of Disaster Risk Reduction, 8, 10-19. https://doi.org/10.1016/j.ijdrr.2013.12.003

[10] García-Ojeda, J.C., Bertok, B., Friedler, F. and Fan, L.T. (2013) Building Evacuation-Route Planning via Time-Expanded Process-Network Synthesis. Fire Safety Journal, 61, 338-347. https://doi.org/10.1016/j.firesaf.2013.09.023

[11] Forcael, E., González, V., Orozco, F., Vargas, S., Pantoja, A. and Moscoso. P. (2014) Ant Colony Optimization Model for Tsunamis Evacuation Routes. Computer-Aided Civil and Infrastructure Engineering, 29, 723-737. https://doi.org/10.1111/mice.12113

[12] Yamamoto, K. and Li, X. (2017) Safety Evaluation Method of Evacuation Routes in Urban Areas in Case of Earthquake Disasters Using Ant Colony Optimization Algorithm and GIS. Journal of Risk and Financial Management, 10, 14. https://doi.org/10.3390/jrfm10030014

[13] Lim, G.J., Rungta, M. and Baharnemati, M.R. (2015) Reliability Analysis of Evacuation Routes under Capacity Uncertainty of Road Links. IIE Transaction, 47, 50-63. https://doi.org/10.1080/0740817X.2014.905736

[14] Cuesta, A., Abreu, O., Balboa, A. and Alvear, D. (2017) Real-Time Evacuation Route Selection Methodology for Complex Buildings. Fire Safety Journal, 91, 947-954. https://doi.org/10.1016/j.firesaf.2017.04.011

[15] Álvarez1, G., Quiroz, M., León, J. and Cienfuegos, R. (2018) Identification and Classification of Urban Micro-Vulnerabilities in Tsunami Evacuation Routes for the City of Iquique, Chile. Natural Hazards and Earth Science Systems, 18, 2027-2039. https://doi.org/10.5194/nhess-18-2027-2018

[16] Lujak, M. and Giordani, S. (2019) Centrality Measures for Evacuation: Finding Agile Evacuation Routes. Future Generation Computer Systems, 83, 401-412. https://doi.org/10.1016/j.future.2017.05.014

[17] Yoshitsugu, N., Abe, S. and Yamamoto, K. (2019) Deriviation Method of Evacuation. Routes Using Physarum Solve. Journal of Information Processing, 60, 2325-2329.

[18] Li, Q., Fang, Z., Li, Q. and Zong, X. (2010) Multi-Objective Evacuation Route Assignment Model Based on Genetic Algorithm. Proceedings of the 18th International Conference on Geoinformatics, Beijing, 18-20 June 2010.

https://doi.org/10.1109/GEOINFORMATICS.2010.5567485 
[19] Łozowicka, D. (2012) Z Using Genetic Algorithms and Genetic Programming in Solving Problems Related to Safety and Evacuation of People from Ships and Land Facilities. Zeszyty Naukowe/Akademia Morska w Szczecinie, 29, 130-133.

[20] Loland, L. and Hansen, B. (2013) Groupwise Evacuation with Genetic Algorithms. Master Thesis, University of Agder, Kristiansand and Grimstad.

[21] Shimura, Y. and Yamamoto, K. (2014) Method of Searching for Earthquake Disaster Evacuation Routes using Multi-Objective GA and GIS. Journal of Geographic Information System, 6, 492-525. https://doi.org/10.4236/jgis.2014.65042

[22] Goerigk, M., Deghdak, K. and Heßler, P. (2014) A Comprehensive Evacuation Planning Model and Genetic Solution Algorithm. Transportation Research Part E: Logistics and Transportation Review, 71, 82-97. https://doi.org/10.1016/j.tre.2014.08.007

[23] Pourrahmani, E., Delavar, R.M. and Mostafavi, M.A. (2015) Optimization of an Evacuation Plan with Uncertain Demands Using Fuzzy Credibility Theory and Genetic Algorithm. International Journal of Disaster Risk Reduction, 14, 357-372. https://doi.org/10.1016/j.ijdrr.2015.09.002

[24] Ikeda, Y. and Inoue, M. (2016) An Evacuation Route Planning for Safety Route Guidance System after Natural Disaster Using Multi-Objective Genetic Algorithm. Procedia Computer Science, 96, 1323-1331. https://doi.org/10.1016/j.procs.2016.08.177

[25] Gomes, R. and Straub, J. (2017) Genetic Algorithm for Flood Detection and Evacuation Route Planning. Proceedings of Algorithms and Technologies for Multispectral, Hyperspectral, and Ultraspectral Imagery XXIII, 10198, 1019816. https://doi.org/10.1117/12.2266474

[26] Li, Y., Cai, W. and Kana, A.A. (2019) Design of Level of Service on Facilities for Crowd Evacuation Using Genetic Algorithm Optimization. Safety Science, 120, 237-247. https://doi.org/10.1016/j.ssci.2019.06.044

[27] National Research Institute for Earth Science and Disaster Resiliense. Disaster Cases Database. http://dil.bosai.go.jp/dedb/

[28] Setagaya Ward. Flood Hazard Map (Tama River Edition) Data. https://www.city.setagaya.lg.jp/mokuji/kurashi/005/003/003/d00005603.html

[29] Hiroshima City. Food Hazard Map. https://www,city.hiroshima.lg.jp/site/saigaiinfo/17890.html

[30] Ministry of Health, Law and Welfare (2020) Dietary Reference Intakes for Japanese: 2020 Edition. Tokyo, Japan.

[31] Geospatial Information Authority of Japan. National Fundamental Geospatial Data. https://www.gsi.go.jp/ENGLISH/page e30031.html 